\title{
UDC 482.32
}

\section{SCOPUS CODE 1101}

https://doi.org/10.36073/1512-0996-2020-4-19-24

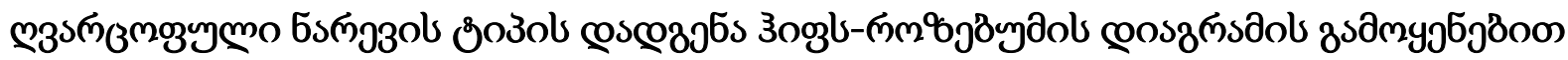

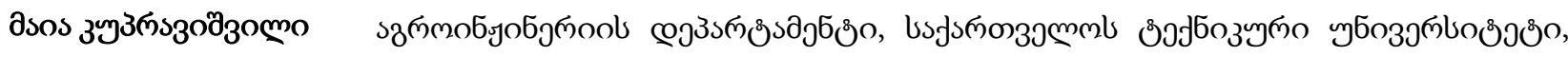

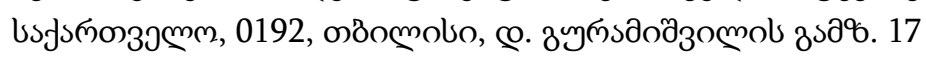 \\ E-mail: m.kupravishvili@gtu.ge
}

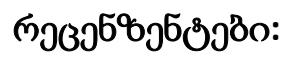

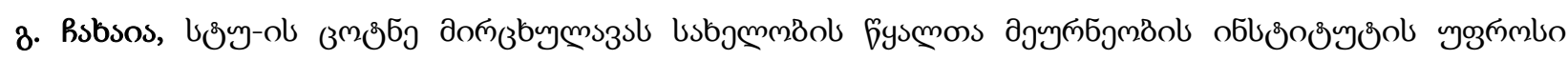

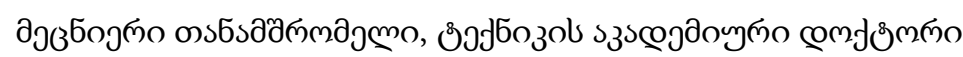

E-mail: gogachaxaia@mail.ru

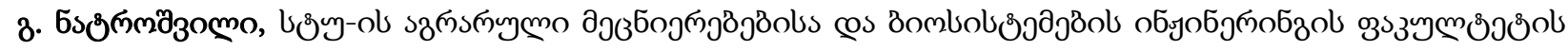

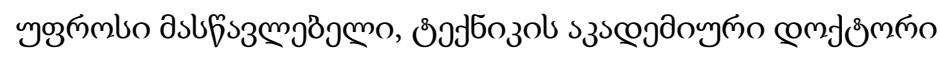

E-mail: g.natroshvili@gtu.ge

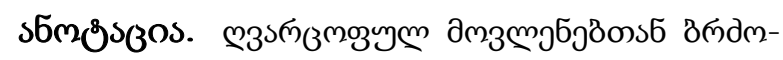
mols cos Зп

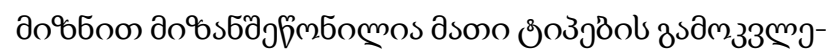

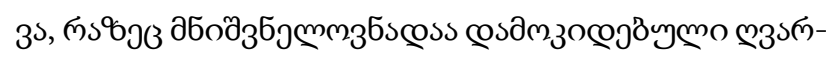

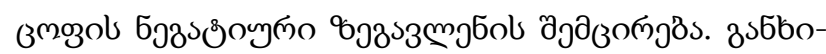

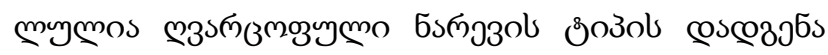

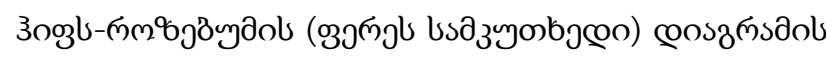

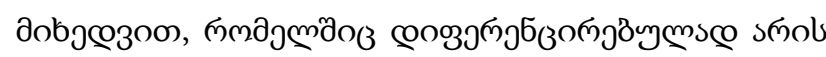

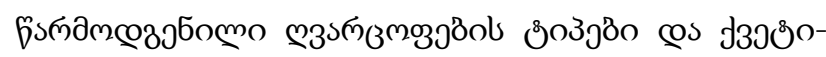

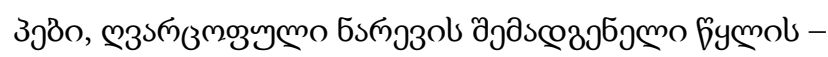

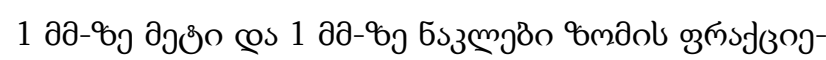

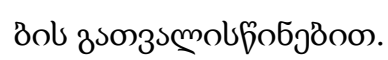

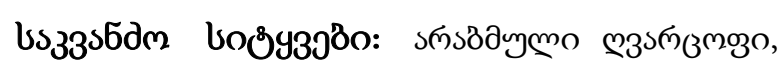

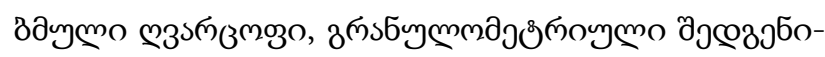

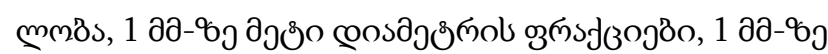

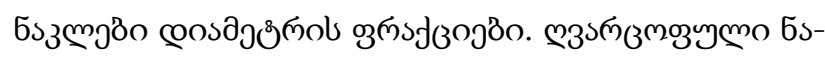

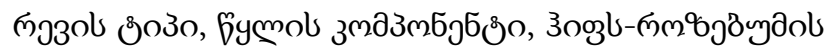
coszmsas.

\section{gjlsзssmo}

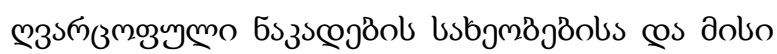

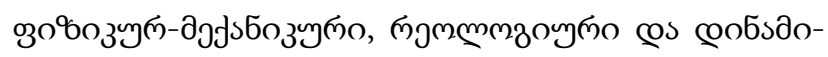

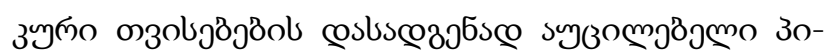

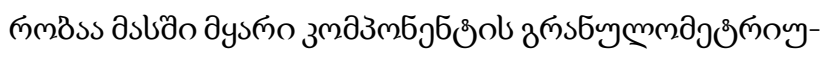




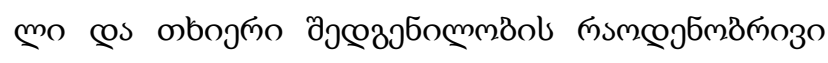

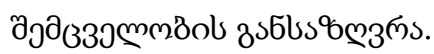

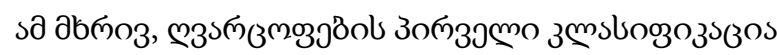

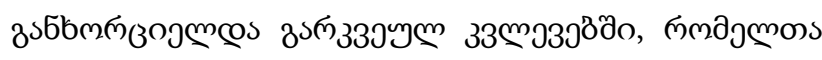

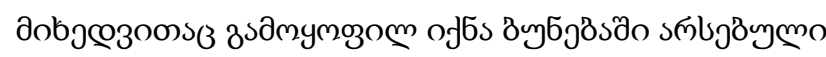

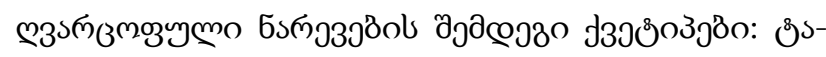

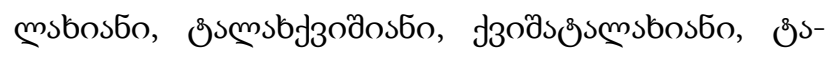

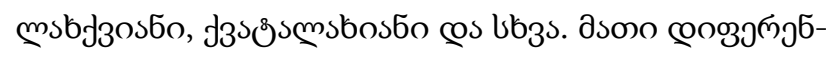

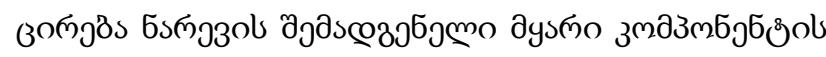

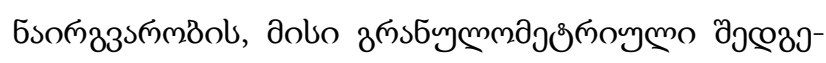

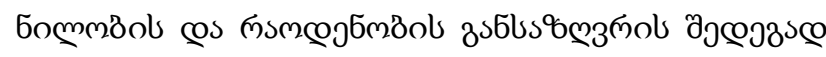

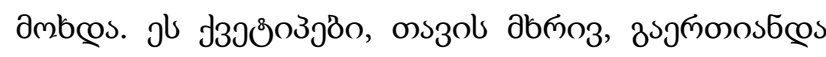

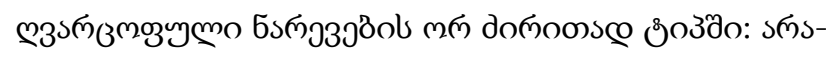

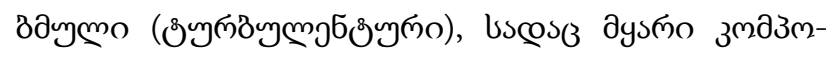

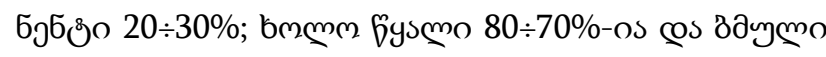

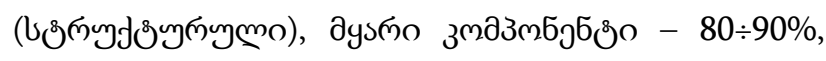

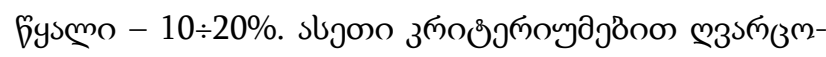
вулмо бsґ

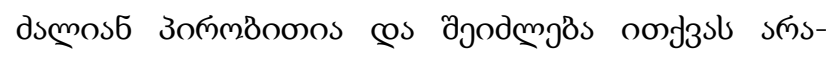
syloso.

\section{domonscon 6sfomo}

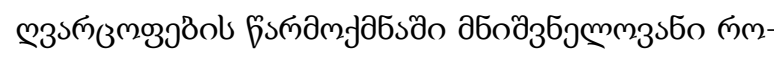

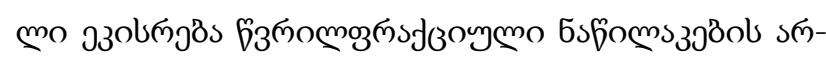

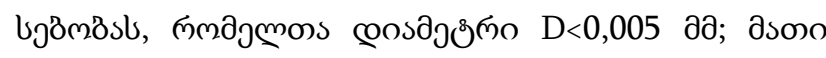

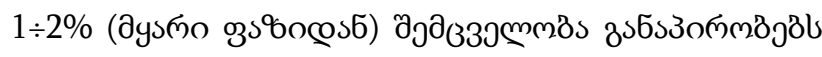

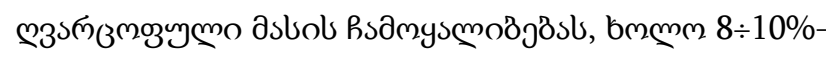

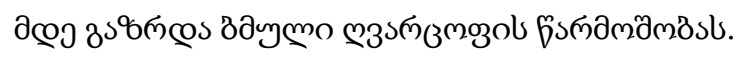

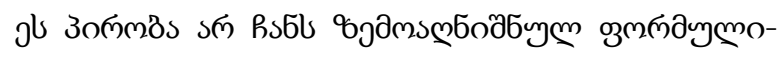

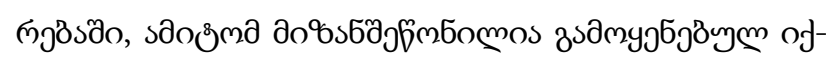

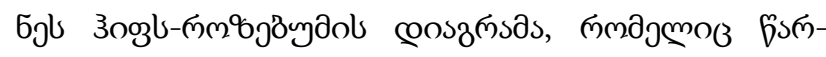

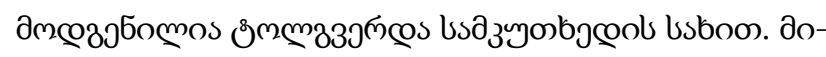

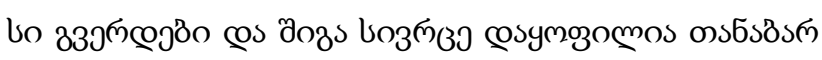

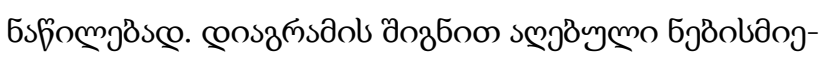

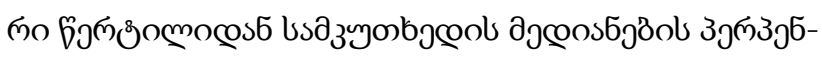

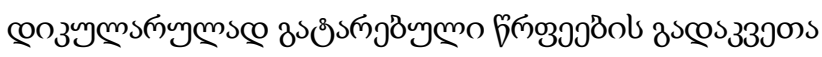

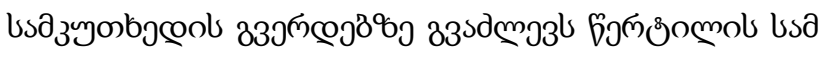

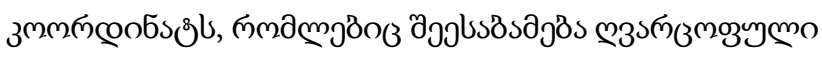

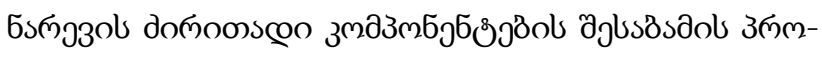

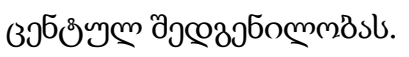

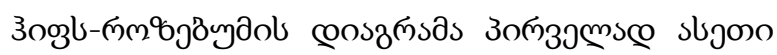

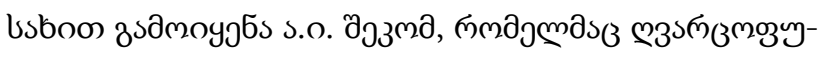

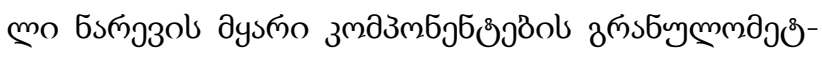

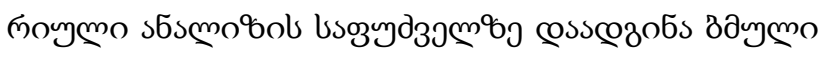

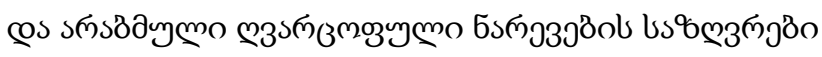

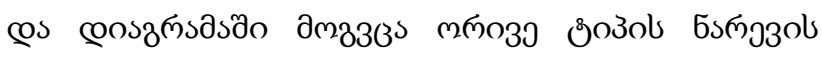

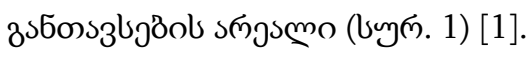

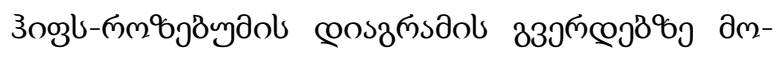

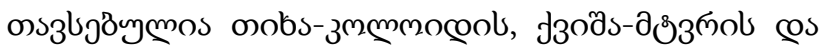

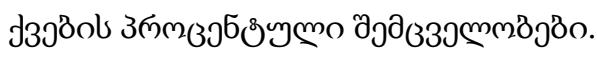

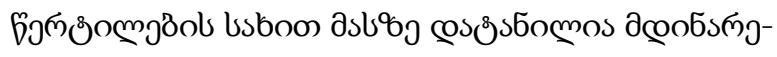

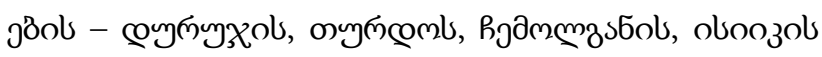

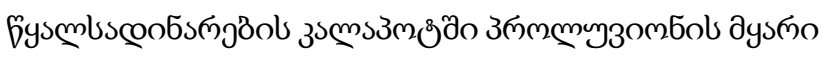

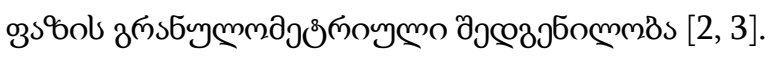

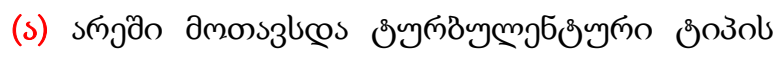

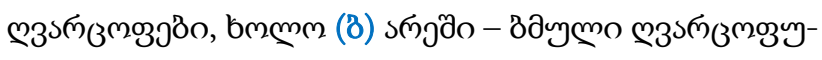

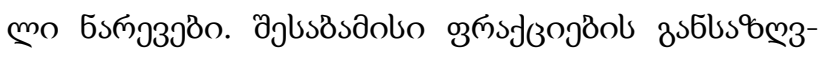

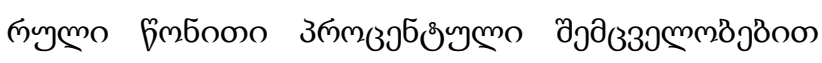

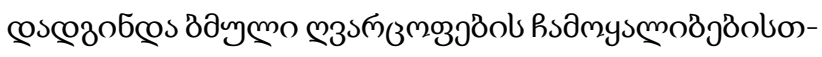

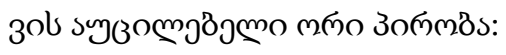

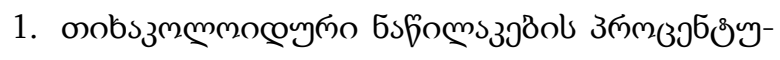

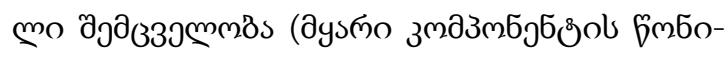

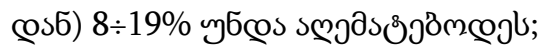




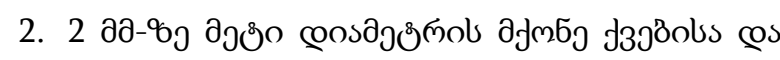

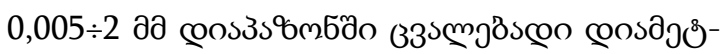

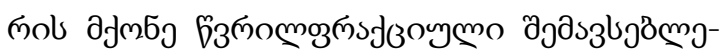

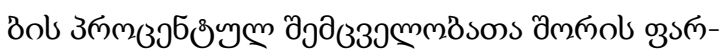

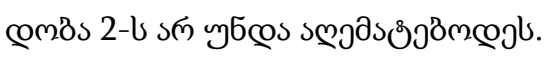

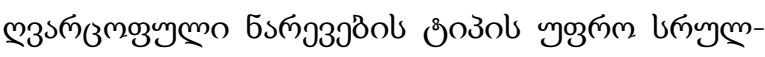

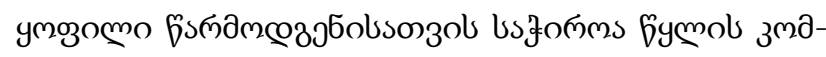

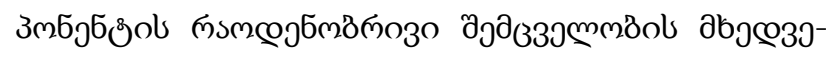

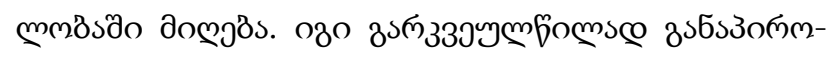

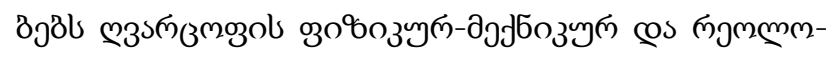

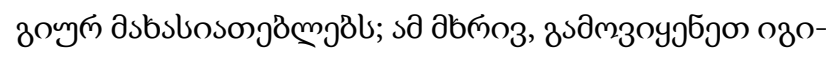

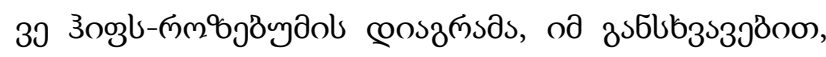

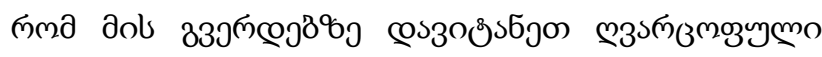

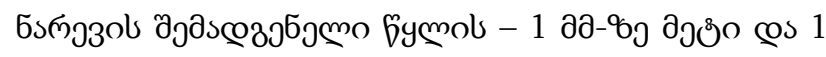

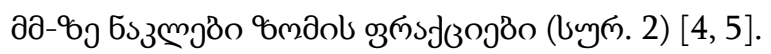

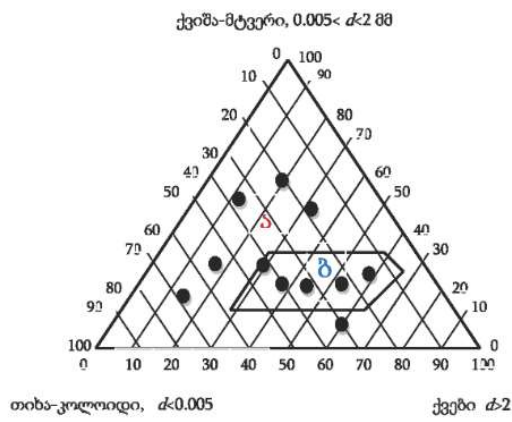

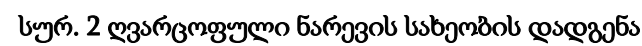

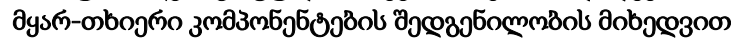

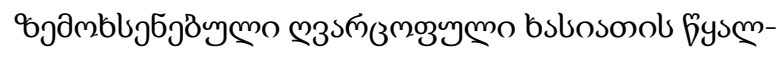

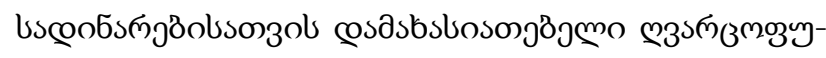

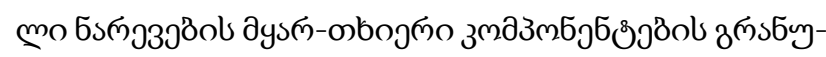

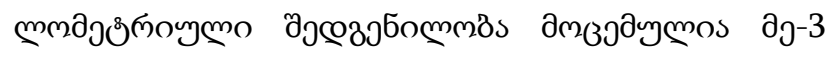
bynsomby.

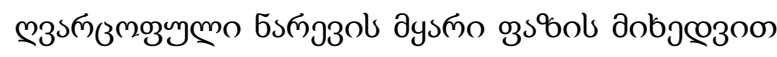

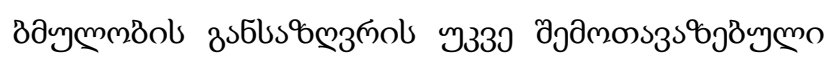

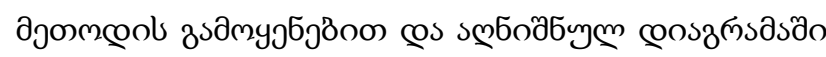

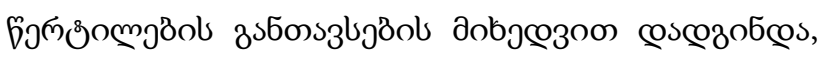

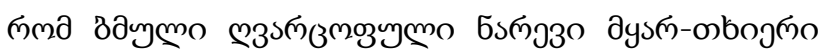

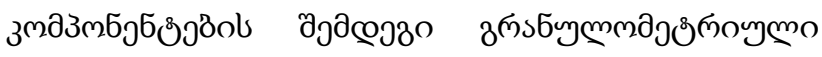

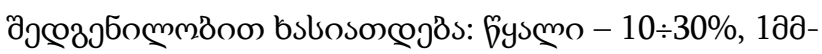

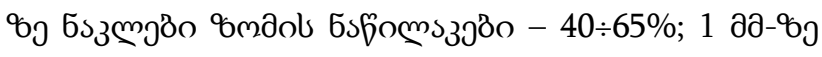

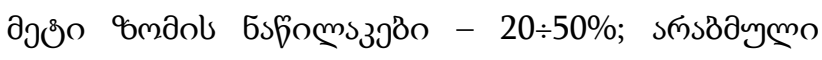

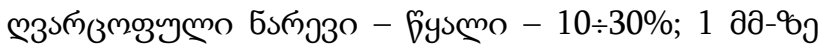

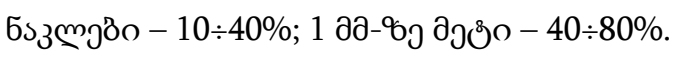

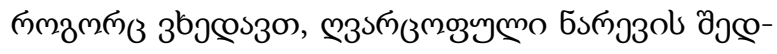

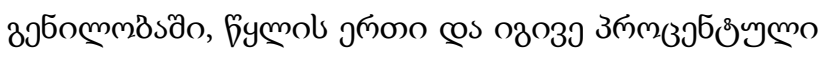

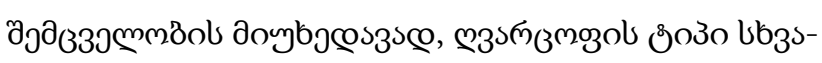

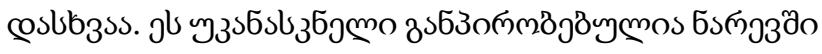

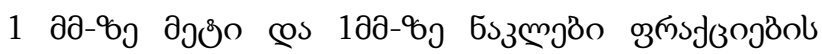

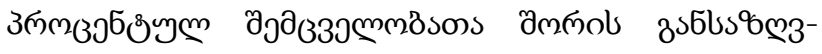

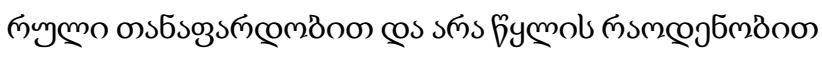

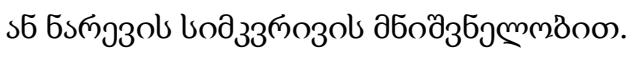

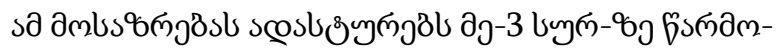

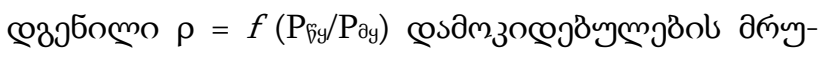

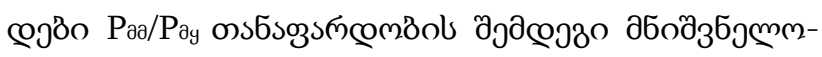
ogöolssomol:

1-эме бодуððо - 0,279; дэ-2 бодуðо - 0,340; дэ-3

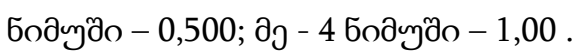

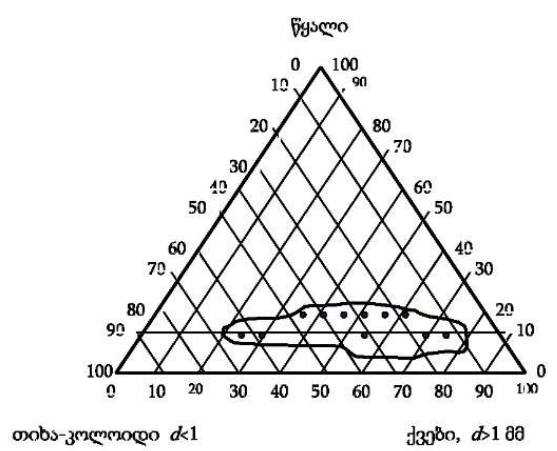

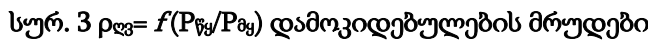

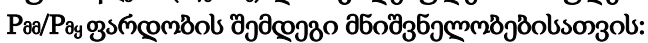
1) 0.270 ; 2) 0.340 ; 3) 0.500 ; 4) 1.00 


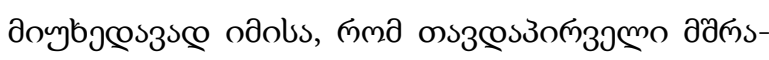

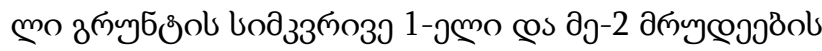

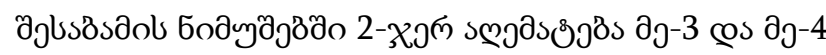

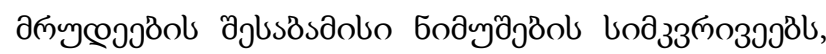

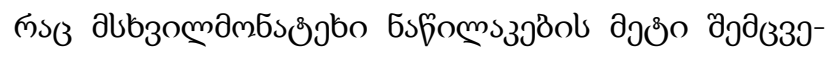

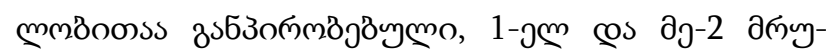

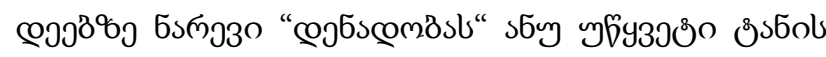

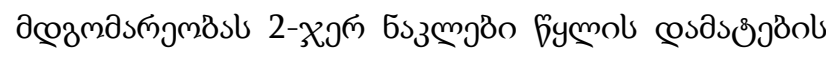

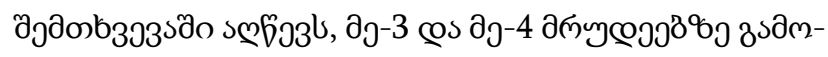

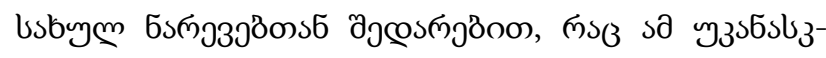

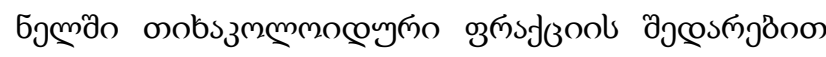

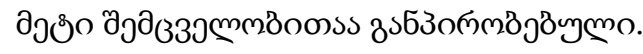

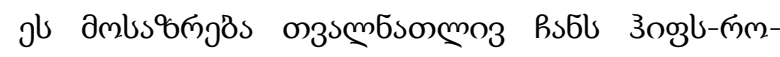

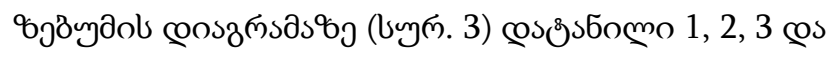

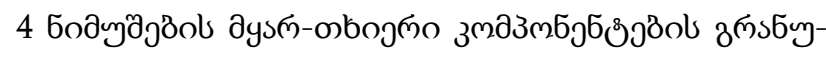

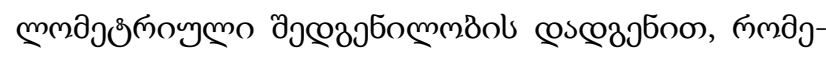

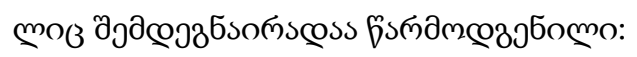

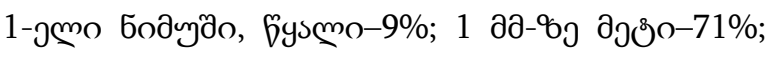

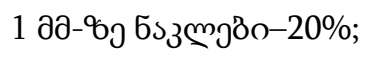

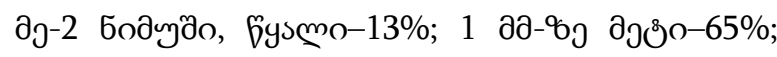

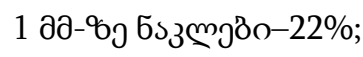

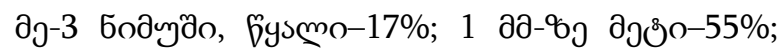

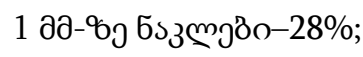

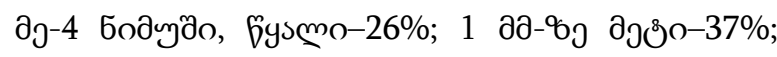

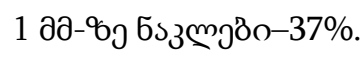

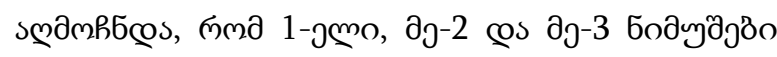

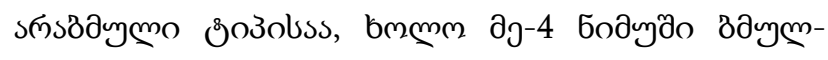

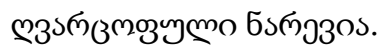

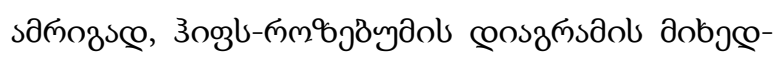

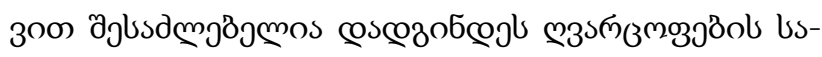

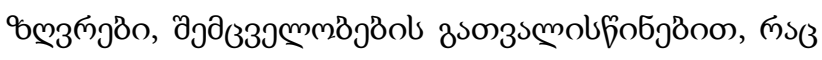

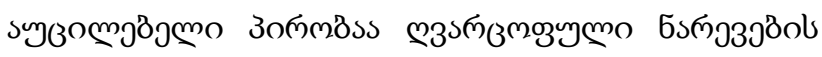

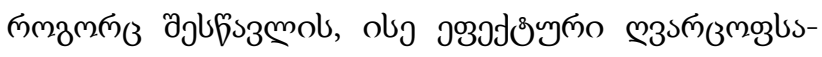

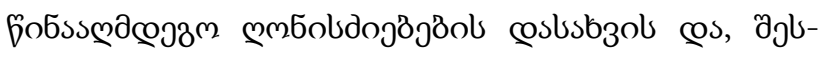

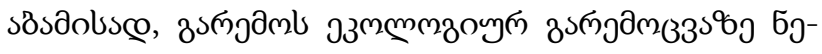

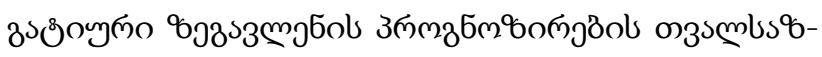
molon.

\section{cosb $33^{6 s}$}

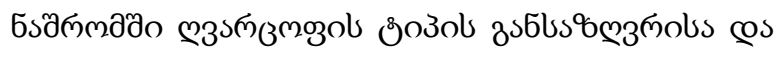

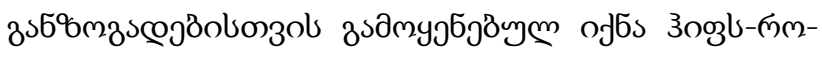

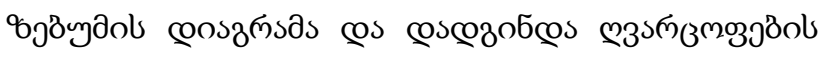

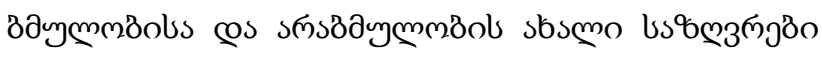

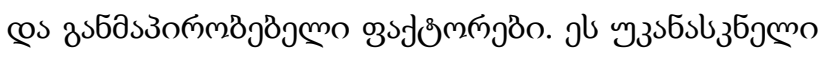

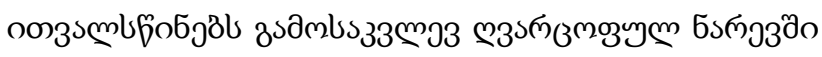

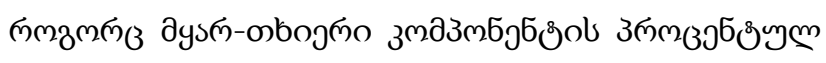

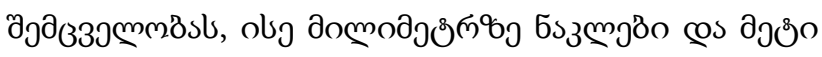

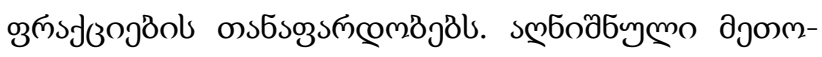

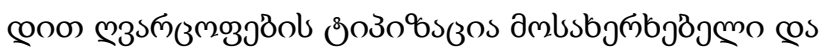

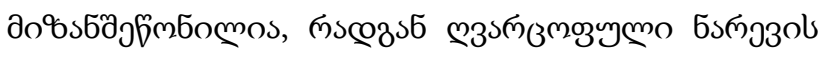

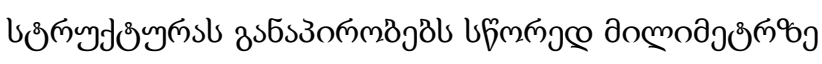

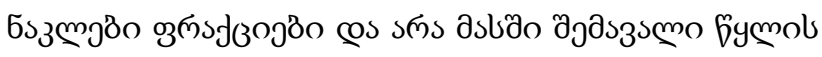

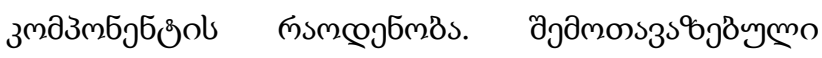

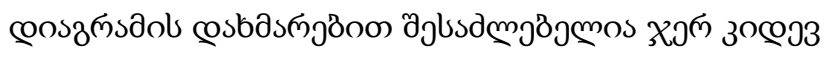

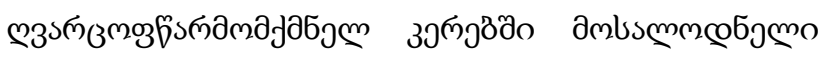

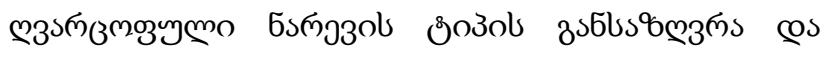

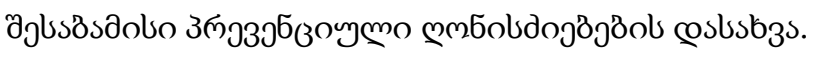




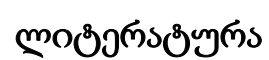

1. Sheko A.I. Patterns of mudflow formation and forecast. M.: "Nedra". 1980, 296 p. (In Russian).

2. Tevzadze V.I. Statistics of cohesive mudflows passing in nature and the values of their main physical, mechanical and hydraulic characteristics. Alma-Ata. 1988, 41-50 pp. (In Russian).

3. Tevzadze V.I. Statistics of movement of mud-flows (highly concentrated) and their physical-mechanical and hydraulic characteristics. Alma-Ata. 1988, 51-55 pp. (In Russian).

4. Kupravishvili M.S. Why mountains cry. Monograph. ISBN: 978-620-2-55486-2. 2020, 69 p.

5. Kupravishvili M.S. Correlation angle of internal friction of the particles with alike diameter. Works of Georgian Technical University. №4, (514). 2019, 75-81 pp. (In Georgian).

UDC 551.515.3

SCOPUS CODE 1101

https://doi.org/10.36073/1512-0996-2020-4-19-24

\section{Determining the type of mudflow mixture using the Gibbs-Roseboom diagram}

Maia Kupravishvili Department of Agro-Engineering, Georgian Technical University, 17 D. Guramishvili Str, E-mail: m.kupravishvili@gtu.ge

\section{Reviewers:}

G. Chakhaia, Academic Doctor of Technical Sciences, Senior Researcher, Tsotne Mirtskhulava Water Management Institute, GTU

E-mail: gogachaxaia@mail.ru

G. Natroshvili, Academic Doctor of Technical Sciences, Senior Teacher, Faculty of Agricultural Science and Biosystems Engineering, GTU

E-mail: g.natroshvili@gtu.ge

Abstract. The Gibbs-Roseboom diagram was used in determining and generalizing the type of mudflow mixture as well as new boundaries between viscous stream and fluid stream were determined in the article. The latter is due to the percentage of solid-liquid component in the mudflow, as well as from fractions of less than one millimeter. Thus, the typification of mudflows is convenient and expedient, since the structure of the mixture is determined by clay-colloidal fractions, and not by the amount of water components in it. Using the proposed diagrams, it is possible to determine the type of mudflow still in the outbreaks and take appropriate preventive measures.

Key words: Fluid stream; fractions of less than $1 \mathrm{~mm}$ diameter; fractions of more than $1 \mathrm{~mm}$ diameter; GibbsRoseboom diagram; granulometric composition; type of mudflow mixture; viscous stream; water component. 


\section{UDC 551.515.3}

SCOPUS CODE 1101

https://doi.org/10.36073/1512-0996-2020-4-19-24

\section{Определение типа селевой смеси с использованием диаграммы Хиббса-Розебома}

Майя Куправишвили департамент агроинженерии, Грузинский технический университет, Грузия, 0192, Тбилиси. пр. Д. Гурамишвили 17

E-mail: m.kupravishvili@gtu.ge

\section{Рецензенты:}

Г. Чахая, старший научный сотрудник Института водного хозяйства им. Цотне Мирцхулава, академический доктор технических наук ГТУ

E-mail: gogachaxaia@mail.ru

Г. Натрошвили, факультет аграрных наук и инженерии биосистем, старший преподаватель, академический доктор технических наук ГТУ

E-mail: g.natroshvili@gtu.ge

Аннотация. Для борьбы с селевыми явлениями и принятия превентивных мер желательно выяснить их типы, от которых в значительной степени зависит снижение негативного воздействия селей. В статье рассмотрено определение типа селевой смеси по диаграмме Хиббса-Розебома (цветовой треугольник), которая различает типы и подтипы селевых потоков с учетом компонентов селевой смеси - воды, с учетом размеров фракций более 1 мм и менее 1 мм.

Ключевые слова: водный компонент, гранулометрический состав, диаграмма Хипси-Розебума, несвязной сель, связной сель, тип селевой смеси, фракции диаметром более 1 мм, фракции диаметром менее 1 мм.

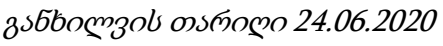

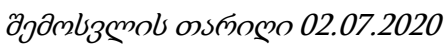

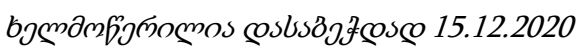

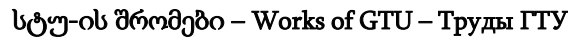

